\title{
Reply to the letter by M. Yoneda et al. regarding "Ezetimibe therapy in patients with nonalcoholic steatohepatitis"
}

\author{
Hyohun Park • Takeshi Okanoue
}

Received: 26 November 2010/ Accepted: 26 November 2010/Published online: 8 January 2011

(C) Springer 2010

We thank Dr. Yoneda and colleagues for their comments on our work [1].

In our study, we demonstrated that long-term ezetimibe therapy caused significant decreases in large very-lowdensity liproprotein (VLDL1), small LDL, very small LDL, and electronegative charge-modified LDL (emLDL). The long-term ezetimibe therapy was associated with significant decreases in the levels of monosaturated fatty acids, especially palmitic acid. Therefore, we reported that the long-term ezetimibe therapy improved nonalcoholic fatty liver disease (NAFLD) through both an improvement of hepatic and systemic vascular insulin resistance and a reduction in the absorption of monosaturated fatty acids. On the other hand, Yoneda et al. reported that the hepatic mRNA expression of microsomal triglyceride transfer protein (MTTP) was increased significantly after ezetimibe treatment for 6 months compared with the baseline, although the molecular mechanismof how ezetimibe increases MTTP mRNA expression remains unclear.

A significant increase of hepatic MTTP mRNA expression is an important possible mechanism by which ezetimibe therapy might exert beneficial effects against NAFLD in humans. We did not investigate hepatic MTTP
mRNA expression in our study. Therefore, we do not have any comments about the induction of MTTP mRNA expression as a mechanism of the improvement of NAFLD.

There might be many factors involved in the progression of simple hepatic steatosis to nonalcoholic steatohepatitis (NASH), including the factors mentioned in our report. Increased MTTP mRNA expression could be one of these factors. Simply from the viewpoint of MTTP function, increased MTTP activity could improve hepatic steatosis. However, it could also increase plasma triglyceride and VLDL levels.

If the effect of ezetimibe in decreasing plasma triglyceride and VLDL levels is strong enough, these levels would not be increased.

\section{Reference}

1. Park H, Shima T, Yamaguchi K, Mitsuyoshi H, Minami M, Yasui $\mathrm{K}$, et al. Efficacy of long-term ezetimibe therapy in patients with nonalcoholic fatty liver disease. J Gastroenterol. 2011;46:101-7.

This author's reply refers to the letter to the editor at doi:10.1007/s00535-010-0356-8.

H. Park $(\bowtie) \cdot$ T. Okanoue

Division of Internal Medicine, Saiseikai Suita Hospital,

Suita, Japan

e-mail: parkh50@hotmail.com 